\title{
Efficiency of Low-Profile External Dumping at Open Pit Coal Mining in Kemerovo Region
}

\author{
Alexey Selyukov ${ }^{1}$, Vyacheslav Ermolaev ${ }^{1}$, and Irina Kostinez $^{2}$ \\ ${ }^{1}$ T.F. Gorbachev Kuzbass State Technical University, Department of open pit mining, Vesennyaya \\ St. 28, Kemerovo city, Russian Federation \\ ${ }^{2}$ T.F. Gorbachev Kuzbass State Technical University, Belovo Branch, 652644 Ilyicha st. 32, Inskoy, \\ Kemerovo oblast, Russia
}

\begin{abstract}
Kemerovo region is one of the largest industrial regions of Russia, with a raw material specialization. The rapid growth of the coal industry in recent years has been greatly facilitated by the expansion and development of open pit mining for coal seams extraction, accompanied by an increase in the volumes of overburden and the height of the dumps. There are about 400 objects in the Russian Federation Government Register of Waste Disposal Facilities $80 \%$ of which are dumps. Approaches both to external dumping and to the technical stage of reclamation currently contribute to the growth of geomorphic system's instability. Thus, it is proposed to slightly change the approaches to external dumping: the essence consists in the formation of an external dump of overburden, which in future would represent a favorable landscape unit of a flat surface relief used for subsequent differently directed purposes.
\end{abstract}

\section{Introduction}

Sustainable development of Kuzbass (Kemerovo region, Western Siberia, Russia) depends both on economic growth and natural environment preservation [1-2]. This problem is quite typical for old mining regions of Europe and Russia [3-6]. Despite implicating new equipment on Kuzbass open pits [7] and technological development of surface mining in the region [8], the practice of open pit coal mining in Kemerovo region shows that the backfilling of overburden dumps by the methods of 1970-1980 sharply reduces the ecological efficiency and raises material and financial costs of coal extraction [9-10]. The area of reclaimed dumps is getting reduced, the area of natural landscape on which the dump is placed is also getting smaller $[11,12,13]$.

When analyzing the technical and economic indicators of the low-profile dump backfilling, it is necessary to find the optimal values of its parameters, such as: transportation distance, height, area and, correspondingly, the land capacity. First, it is needed to set the required amount of overburden, which will later contain the dump. Secondly, it is required to find the most convenient location of the future dump with a minimum range of transportation from the quarry to its most remote point. The dump should be located taking into account the surface relief and factors (water resources, geological conditions, etc.) affecting 
the convenience and the possibility of overburden disposal in the place of its perspective storage.

\section{Materials and methods}

Taking into account the performance of other models, it is possible to estimate the economic efficiency of designing a low-profile dump. Efficiency lies in the best combination of geomechanical, ecological and operational components of the area dump backfilling compared to the pyramidal technology which is common for Kuzbass. Also, this dumping pattern allows optimizing the process of overburden transportation from the quarry to the dump taking into account the variation in the transportation distance that is, reducing or increasing the transportation distance from the largest to the smaller, depending on the overall technical and economic situation of the mining enterprise. Another reason to consider the low-profile external dumping is increasing dump's stability as an important ecological factor [14-15].

Let's consider the effectiveness of low-profile dumping on the example of the Tersinsky geological and economic area. The projected open pit spreads from the south-west to the northeast. Its area is 510.7 hectares with a length of $4.5 \mathrm{~km}$ and a width of $1.5 \mathrm{~km}$, and its maximum depth varies from $260 \mathrm{~m}$ to $180 \mathrm{~m}$, depending on the topography of the surface. Considering the volume of rock mass extracted from the quarry (about 800 million $\mathrm{m} 3$ ), and the average stripping ratio $\left(10\right.$ tons $\left./ \mathrm{m}^{3}\right)$, it was calculated that the reserves within the licensed boundaries vary in the range of 60-80 million tons. A quarry with such a number of reserves can be attributed to the average - with a production capacity of 3-5 million tons per year. Thus, taking into account the volume of coal reserves and the possible production capacity, we conclude that the life of the quarry is approximately 20 years, without taking into account development and damping.

The initial height of the dump is formed on the basis of the surface relief, the optimum ratio of its capacity (volume, $\mathrm{m}^{3}$ ) and the transportation distance (length, km). For an example of calculations, we take an even surface and a quarry, located next to the dump. Depending on the volume of rock mass extracted from the open pit mime, the area and height of the future dump are calculated. The relief feature of the coal deposit allows us to place the dump considering the difference between the lowest and the highest points on the surface. Backfilling the hollows with overburden will not only allow making the dump more stable, but also creating an absolutely flat horizontal platform with the option of further use for any industrial or civil purposes. The dump placement can be carried out in narrows and hollows at a distance from the quarry not exceeding the economically advantageous transportation length. With the use of AutoCAD CIVIL 3D software, the body of the dumps was projected (Fig. 1a, b) and its capacity and occupancy were calculated (Table 1). The average transportation distance did not exceed $5 \mathrm{~km}$.

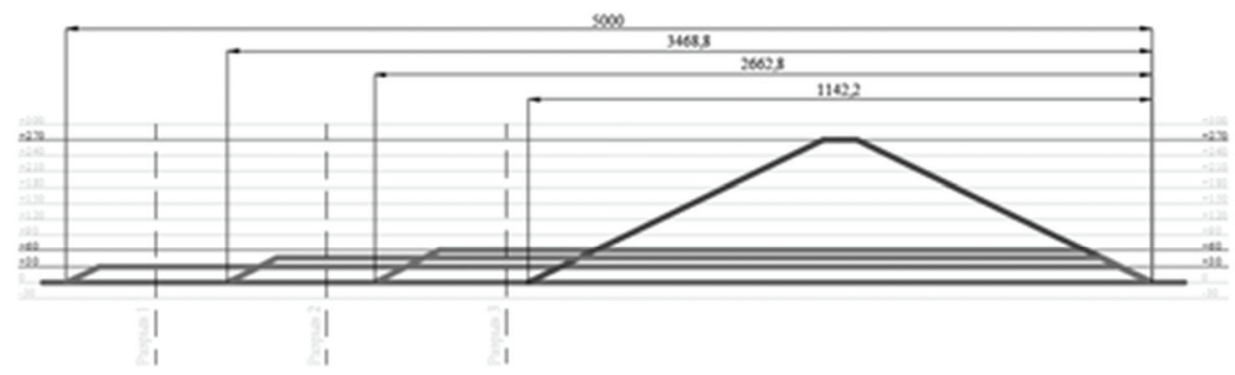




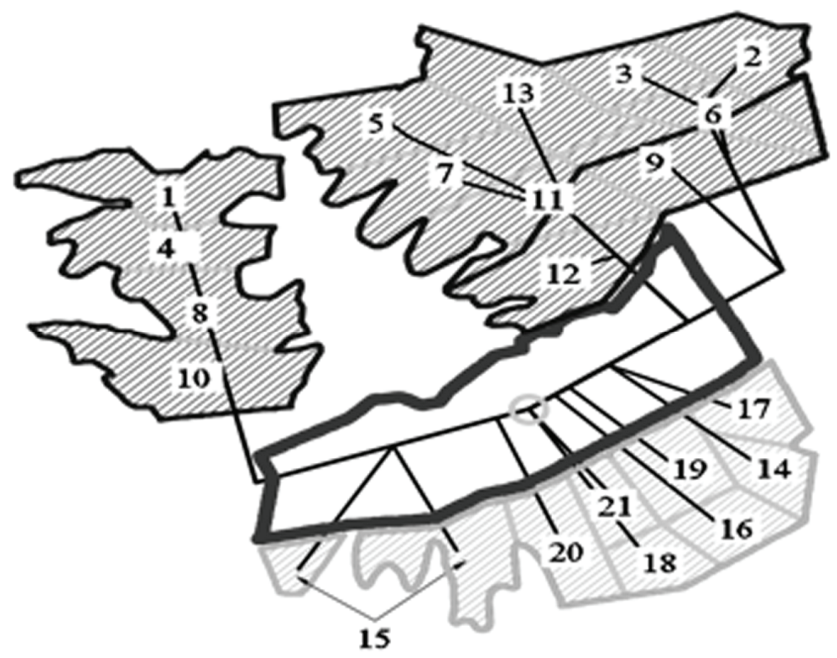

Fig. 1. a) Profiles of projected low-profile and pyramid dumps; b) plan for distributing the parts of the backfill of the reformed low-profile dump by years with tracing to each section

Table 1. Low-profile dump parameters

\begin{tabular}{|c|c|c|c|c|c|c|c|c|c|}
\hline \multirow{3}{*}{$\begin{array}{c}\text { Year of } \\
\text { backfilling }\end{array}$} & \multicolumn{3}{|c|}{$\begin{array}{c}\text { Overburden volume, } \\
\text { million } \mathbf{~ m}^{3}\end{array}$} & \multicolumn{3}{|c|}{$\begin{array}{c}\text { Area of dump's part, } \\
\text { hectares }\end{array}$} & \multicolumn{3}{|c|}{$\begin{array}{c}\text { Transportation distance, } \\
\text { km }\end{array}$} \\
\hline & \multicolumn{3}{|c|}{ Body } & \multicolumn{3}{|c|}{ Body } & \multicolumn{3}{|c|}{ Body } \\
\hline & 1 & 2 & 3 & 1 & 2 & 3 & 1 & 2 & 3 \\
\hline 1 & 34.9 & & & 102.5 & & & 5.5 & & \\
\hline 2 & & 36.6 & & & 82.5 & & & 5.2 & \\
\hline 3 & & 36 & & & 58.7 & & & 5.1 & \\
\hline 4 & 34.6 & & & 86.7 & & & 5 & & \\
\hline 5 & & 37.1 & & & 105.1 & & & 4.9 & \\
\hline 6 & & 35.7 & & & 106.1 & & & 4.4 & \\
\hline 7 & & 35 & & & 60.2 & & & 4.3 & \\
\hline 8 & 35.4 & & & 101.8 & & & 4.3 & & \\
\hline 9 & & 40.2 & & & 89.9 & & & 4.3 & \\
\hline 10 & 37.2 & & & 108.9 & & & 4 & & \\
\hline 11 & & 32.2 & & & 134 & & & 3.5 & \\
\hline 12 & & 36.5 & & & 111 & & & 3.4 & \\
\hline 13 & & 31.1 & & & 113.3 & & & 3.1 & \\
\hline 14 & & & 30.4 & & & 45.6 & & & 2.5 \\
\hline 15 & & & 27.5 & & & 110.5 & & & 2.5 \\
\hline 16 & & & 29 & & & 49.3 & & & 2.2 \\
\hline 17 & & & 27.6 & & & 48.5 & & & 2.1 \\
\hline 18 & & & 28.2 & & & 43.3 & & & 1.9 \\
\hline 19 & & & 29.9 & & & 67.7 & & & 1.6 \\
\hline 20 & & & 28.4 & & & 71.1 & & & 1.6 \\
\hline 21 & & & 28.9 & & & 40.5 & & & 1.4 \\
\hline \multirow{2}{*}{ Total } & 142.1 & 320.4 & 229.9 & 399.9 & 860.8 & 476.5 & \multicolumn{3}{|c|}{ Average $=3.5$} \\
\hline & & 692.4 & & & 1737.2 & & & & \\
\hline
\end{tabular}




\section{Results and discussion}

From Table 1 it can be seen that, along with a decrease in the average length of transportation, the area of land that is leased under the dump is also decreasing, which will also bring a positive impact on the economic performance of the low-profile dump with the given layout of the dump bodies.

The option of a step-by-step layout of the low-profile dump also gives us the opportunity to start backfilling from the most remote point of the projected dump and to reduce the transportation length as the pit is deepened, thereby maintaining a balance and helping to regulate the technical and economic performance over the quarry life. This cannot be achieved by backfilling a pyramid dump. Also, when planning a low-profile dump, it becomes possible to lease a site for a part of the dump for a short time, and after backfilling, shrinking and reclamation of a dump site, immediately return it for further alternative use. Thus, we economically exploit leased territory and in a short time we return some of the lands environmentally suitable and economically feasible for farming or subsequent development. To reduce overburden transportation distance, it is proposed to transfer the projected areas to the dump from the longest distances to shorter distances. This will reduce both the peak values of each of transportation distances and their average value (Fig. 2).

Graphical analysis and modeling have shown that the most rational option for reducing the transportation distance is the transfer and placement of the dumping rock volume from the dump bodies located from the north of the open pit to the body of the dump projected in the southern part of it. Moving a part of the dump from the north side jf the pit to the southern part, we reduce the transportation distance (Fig. 3).

Re-planning of the dump bodies is carried out depending on the location of a particular site and its distance from the pit from larger to smaller. This makes possible to more flexibly adjust the backfilled overburden into the low-profile dump (reformed) by introducing a new body and adjust it to the required volume. Along with the decrease in the average transportation range, the area of land leased for filling (Table 1) also decreases.

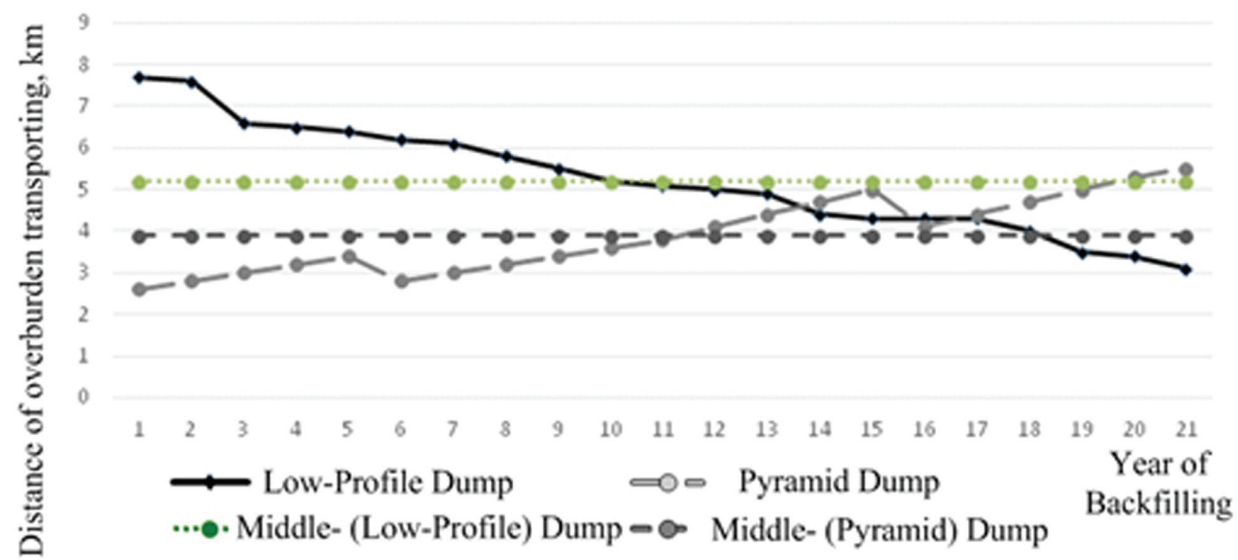

Fig. 2. Comparing the transportation distances for low-profile and pyramid dumps 


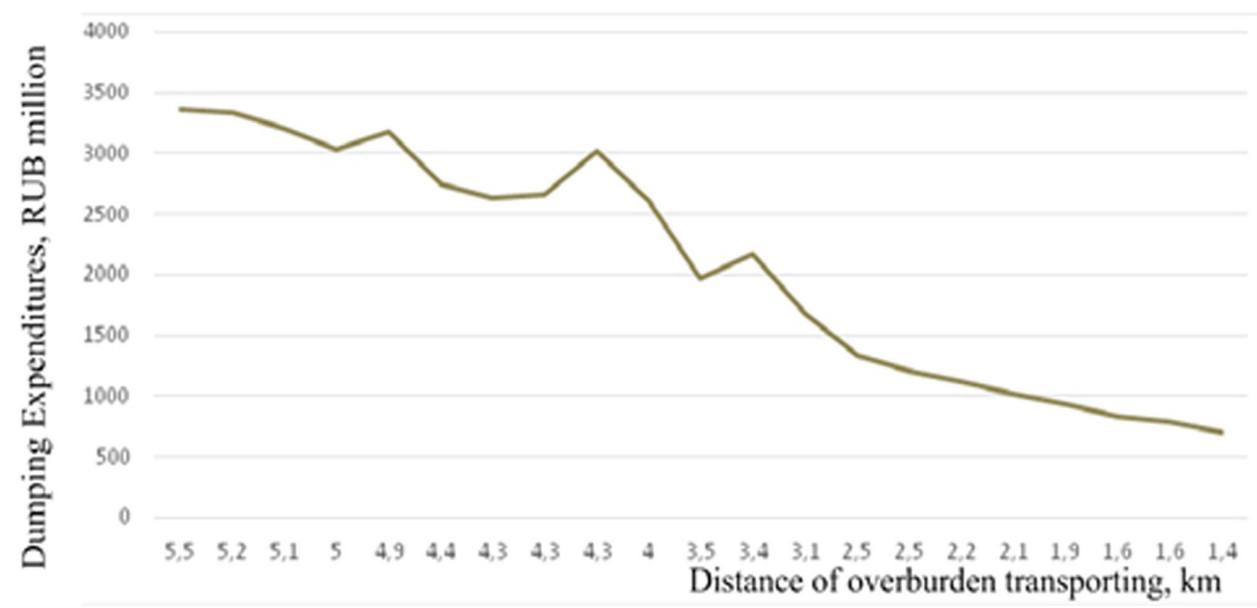

Fig .3. The dependence of transportation expenditures on the transportation distance

Table 2. Summary table of dump backfilling expenditures

\begin{tabular}{|c|c|c|}
\hline & Pyramid dump & Low-profile dump \\
\cline { 2 - 3 } & RUB million & RUB million \\
\hline Land leasing & 1062.2 & 868.6 \\
\hline Transportation & 68613.48 & 43560.3 \\
\hline Leveling & 4317.1 & 3994.6 \\
\hline Reclamation & 1062.15 & 868.6 \\
\hline Total & 75055 & 49292 \\
\hline
\end{tabular}

It can be seen from the graph in Fig. 3 and Table 2 that the main part of the costs is connected with overburden transportation and much exceeds other costs: leasing, leveling, reclamation. Therefore, the cost of overburden transporting in the dumps is considered to be top priority and dominant. Reduction of transportation costs is possible in different ways. If the backfilled low-profile dump is placed along the open pit on both sides, it becomes possible to significantly reduce the transportation distance and the associated costs. Lowprofile dump makes it possible to regulate the range of transportation, taking into account the deepening of the open pit. The pyramid dump is deprived of the possibility of a thorough planning of the surface taking into account the development of open pit mining operations in an upright direction.

\section{Conclusion}

The system of step-by-step backfilling allows conducting dump's local reclamation and lease of land for overburden storage for shorter time periods, and reclaimed lands can yield income from alternative land use, giving an advantage to this scheme of dumping in economic and social development. The geomechanical stability of the low-profile dump excludes the possibility of man-made disasters, such as landslides, mudflows, etc., and also avoids additional costs of cumulative risk factor and protects the enterprise from adverse economic and technical consequences.

\section{References}


1. V. Trifonov, O. Loyko, D. Nesteruk, S. Zhironkin, E. Strekovtsova, AIP Conf. Proceed., 1800, 050009 (2017)

2. A.V. Kapitskaya, I.N. Paskar, Economics and Innovation Management, 1, 39-44 (2017) DOI: 10.26730/2587-5574-2017-1-39-44

3. O. Erdem, T. Güyagüler, N. Demirel, J. Sout. Afr. Inst. Min. Met., 112:5, 405-412 (2012)

4. M. Cehlár, L. Mihok, Theor. Emp. Res. Urb. Man., 8:4, 60-72 (2013)

5. M. Erkayaoğlu, N. Demirel, J. Env. Man., 174, 1-6 (2016)

6. M. Cehlár, J. Janočko, Z. Šimková, T. Pavlik, E3S Web of Conf., 15, 01019 (2017)

7. M.A. Tyulenev, S.A. Zhironkin, O.I. Litvin, E.A. Tyuleneva, O.V. Zhironkina, S.O. Markov, Geotech. Geol. Eng. 35:5, 2065-2077 (2017)

8. M. Tyulenev, S. Zhironkin, E. Tyuleneva, A. Abay, S. Anyona, M. Hellmer, Coal Int., 265:3, 30-34 (2017)

9. M.A. Tyulenev, T.N. Gvozdkova, S.A. Zhironkin, E.A. Garina, Geotech. Geol. Eng., 35:1, 203-212 (2017)

10. T. Gvozdkova, E. Kuznetsov, A. Rudakova, S. Markov, E3S Web of Conf., 15, 01008 (2017)

11. A.V. Selyukov, Advanced technology based on new technological and organizational principles of spatial development of front of mining operations at open pits (Taishan Academic Forum - Project on Mine Disaster Prevention and Control, 2014)

12. A.V. Selyukov, J. Min. Sci. 51:5, 879-887 (2015)

13. A.V. Selyukov, Bulletin of the Tomsk Polytechnic University, Geo Assets Engineering, 326:12 (2015)

14. S. Markov, M. Tyulenev, O. Litvin, E. Tyuleneva, E3S Web of Conf., 15, 01011 (2017)

15. I. Túnyi, D. Vass, S. Karoli, J. Janocko, E. Halásová, A. Zlínská, B. Beláček, Geol. Carp., 56:3, 273-384 (2005) 